\title{
Progress in fluidized bed assisted abrasive jet machining (FB-AJM): Internal polishing of aluminium tubes
}

\author{
Massimiliano Barletta*, Stefano Guarino, Gianluca Rubino, Vincenzo Tagliaferri \\ Department of Mechanical Engineering, University of Rome "Tor Vergata", Via del Politecnico, 1-00133 Rome, Italy \\ Received 8 March 2006; received in revised form 5 June 2006; accepted 12 June 2006 \\ Available online 25 July 2006
}

\begin{abstract}
This paper deals with the internal finishing of tubular components made from a high strength aluminium alloy (AA 6082 T6) using a fluidized bed assisted abrasive jet machining (FB-AJM) system.

Firstly, a Taguchi's experimental plan was used to investigate the influence of abrasive jet speed, machining cycle, and abrasive mesh size on surface roughness and material removal trends. Secondly, the leading finishing mechanisms were studied using combined $3 \mathrm{~d}$ profilometer-SEM analysis to monitor the evolution of the surface morphology of machined workpieces. Finally, the circumferential uniformity and precision machining of the inner surface of workpieces were tested by evaluating the values of the more significant roughness parameters in different circumferential locations.

Consistent trends of surface roughness vs. operational parameters were measured, and significant material removal was found to affect the workpieces during machining. As a result, FB-AJM was found to preferentially machine the asperities and irregularities of the surface, thereby altering the overall surface morphology producing more regular and smoother finishing. Moreover, the good circumferential uniformity and machining accuracy FB-AJM guarantees even on ductile aluminium alloy workpieces ensure that this technology can be applied to a diverse set of industrial components.
\end{abstract}

(C) 2006 Elsevier Ltd. All rights reserved.

Keywords: Fluidized bed; Abrasive jet machining; Internal finishing; Aluminium alloy

\section{Introduction}

This paper examines the application of a relatively new technology, fluidized bed abrasive jet machining (FBAJM), to the finishing of the inner surface of tubular workpieces made from a high yield strength aluminium alloy (AA 6082 T6).

Whenever workpieces made from highly resistant materials or characterized by high ratios of length $L$ to diameter $D(>20)$ must be machined, machining and internal finishing of inner surface in tubular parts can represent a critical and time-consuming stage of the manufacturing process [1]. Most standard machining processes use highspeed turning as the first machining stage followed by grinding using appropriately shaped tools to obtain the desired surface quality [1]. Nevertheless, when highly

\footnotetext{
${ }^{*}$ Corresponding author. Tel.: + 390672597168; fax: + 39062021351.

E-mail address: barletta@mail.mec.uniroma2.it (M. Barletta).
}

resistant materials or workpieces with very long and narrow inner surfaces must be processed, the conventional solutions are affected by several problems. Severe tool vibration, large bending, and tool failure can compromise both the machining and the finishing stage of the manufacturing process [1], therefore increasing the demand for advanced alternative non-conventional technological solutions [2].

Several advanced and non-conventional machining solutions able to process tubular workpieces are reported in the scientific literature, which detail mechanisms of material removal, typologies of energy source, as well as cutting tools and transfer media used in each process [3]. Accordingly, useful studies can easily be found in the specialized literature [4-6], classifying the most suitable solutions according to workpiece features. However, when high precision finishing on highly resistant materials or workpieces with complex geometry is required, most of the advanced polishing methods suffer from various limita- 
tions. For example, techniques based on abrasive flows and jets such as abrasive jet machining (AJM) [4], abrasive flow machining (AFM) [5], and abrasive magnetic flow machining (AMFM) [6]) could only guarantee reasonable results. At the same time, of all the techniques based on abrasive flows and jets, AJM seems to be the most competitive as it requires shorter start-up times as well as lower investment and running costs [1].

There are several papers in the literature in which AJM is used for finishing purposes. Most of these studies argue over the hydrodynamic characteristics of abrasive jets [7-14]; hence, ascertaining the influence of all operational variables on process effectiveness including abrasive type, size and concentration [7-9], impact speed [10], and angle [11]. Other papers found new problems concerning carrier gas typologies, nozzle shape, size and wear, jet velocity and pressure, stand-off-distance (SOD), or nozzle-tip-distance (NTD) [12-14]. These papers express the overall process performance in terms of material removal rate, geometrical tolerances and surface finishing of workpieces, as well as in terms of nozzle wear rate. Finally, there are several significant and important papers which focus on either leading process mechanisms in machining of both ductile and brittle materials [15-18], or on the development of systematic experimental-statistical approaches [19-20] and artificial neural networks [21-22] to predict the relationship between the settings of operational variables and the machining rate and accuracy in surface finishing.

It seems clear from the literature that even though AJM involves the least investment and has the lowest running costs, and does not suffer from any problems associated with the use of solid tools (vibrations, inflexions, or failures), processing time is short, and it enjoys good operational flexibility, it suffers from several drawbacks. These are caused by the hydrodynamic characteristics of the abrasive jet, making this process unsuitable for most tubular shaped parts. Precision machining can be virtually impossible using AJM [23-24], and operating problems can arise including the reach of chocking regimes, significant nozzle wear, fines dispersed in the atmosphere as well as continuous demand for abrasive replacement [25-26].

As an alternative to AJM, Barletta et al. tested the relatively novel hybrid technology of FB-AJM for the first time using tubular workpieces $(L / D \leqslant 20)$ made from high strength stainless steel [27]. This technology uses the peculiar fluidized bed hydrodynamic to improve the abrasive feeding system, the uniformity of abrasive distribution through the workpiece, and the recovery and self-regeneration of abrasive during machining. Consequently, precision and uniform machining as well as accurate surface finishing can be achieved even on inner surfaces of tubular parts [27]. Nevertheless, several concerns regarding the possibility of extending this technology to different and widely used metal alloys as well as to machining very long and narrow tubular parts $(L / D>20)$ still remain unresolved.
This was therefore the context in which the evaluation of how applicable FB-AJM is to internal finishing of highstrength aluminium alloy (AA 6082 T6) using workpieces with ratio $L / D$ greater than 20 took place. Furthermore, details are also provided for the development of a 'built ad hoc' experimental set-up, the execution of tests on various workpieces, the interpretation of the evolution of material removal and surface roughness parameters over process variables, and the establishment of reliable correlations between process settings and machining effectiveness. A Taguchi's reduced experimental plan was executed in order to evaluate the influence of the main operational variables, i.e. abrasive mesh size, machining cycle and jet speed, mass removal, and surface roughness. As a result of the preliminary experimental plan, the first consistent trends of material removal and average roughness according to operational variables were obtained. A standard test condition was also identified and was subsequently applied to study the evolution of roughness parameters of machined surfaces according to mesh size of abrasive media for the purpose of achieving best finishing operating conditions. Moreover, the leading process mechanisms, which concurrently determine material removal and better surface finishing, were interpreted in the light of the surface morphology evolution which was studied by using combined SEM $-3 \mathrm{D}$ profilometer analysis. Finally, the circumferential uniformity and precision of FB-AJM on the workpiece inner surfaces were tested in different locations, thereby definitively assessing the reliability and reproducibility of this technology.

\section{Methods}

\subsection{Fluidized bed assisted abrasive jet machining (FB- AJM) system}

The experimental apparatus used to perform FB-AJM on the aluminium alloy tubes is shown in Fig. 1, and its main characteristics are specified in Table 1. A full depiction of the experimental apparatus is reported in a previously published related paper [27]. Briefly, the apparatus used in this study was an integral system composed of a compressor, two fluidized beds and related systems of three way valves, a nozzle and Venturi's pipes, a couple of abrasive tanks and related valves, tubes and instruments of measurement and control. In addition, using a specific control system meant all the operating settings and air and abrasive fluxes could be regulated.

Supplying compressed air, as working fluid, at moderate pressure $(<1$ bar $)$ to one of the two fluidized beds means the abrasive, previously fed to the fluidized bed from the abrasive tank, is suspended (i.e. taken in a fluid-like state) due to the action exerted by the aerodynamic push of air. Simultaneously supplying further compressed air at high pressure (up to 16 bar) to the three-way valve located in front of the Venturi's pipe connected to the chosen fluidized bed, the suspended abrasive is quickly sucked 

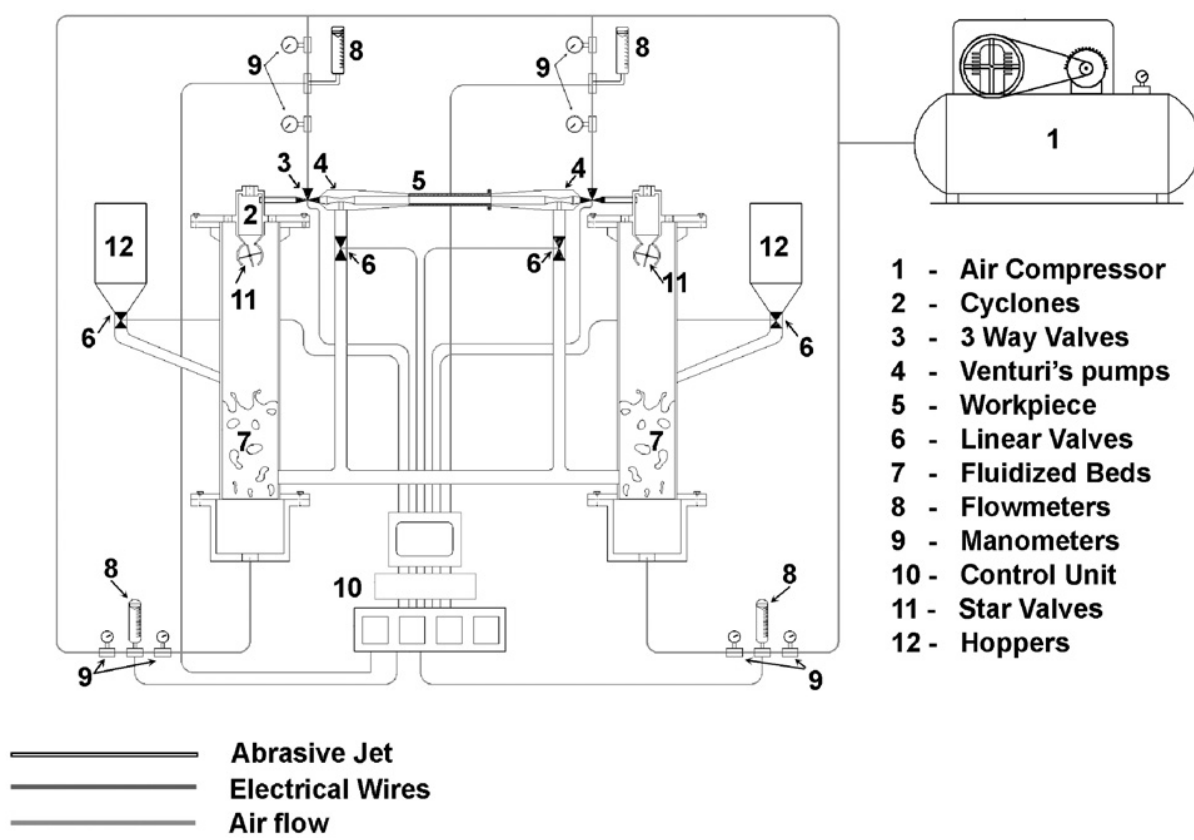

Fig. 1. Fluidized bed assisted abrasive jet machining (FB-AJM) system.

Table 1

Specification of FB-AJM system

\begin{tabular}{ll}
\hline Nozzle & F $10 \mathrm{~mm}$ \\
Abrasive feed hose & F $10 \mathrm{~mm}$ \\
$\begin{array}{l}\text { Discharge pipe } \\
\text { Working fluid (fluidization } \\
\text { air + jet fluid) }\end{array}$ & F $10 \mathrm{~mm}$ \\
Pressure gauge & Air, max $8-10 \mathrm{~atm}, 130 \mathrm{~m}^{3} \mathrm{~h}^{-1}$ \\
Fluidized bed & $0-16 \mathrm{~atm}$ \\
Packed bed & Diameter F $140 \mathrm{~mm}$, height $1200 \mathrm{~mm}$ \\
Workpiece size & Height $180 \mathrm{~mm}(5 \mathrm{~kg})$ \\
Workpiece material & Length $350 \mathrm{~mm}$, inner diameter $10 \mathrm{~mm}$ \\
& AA $6082 \mathrm{~T} 6$
\end{tabular}

up the fluidized bed to the nozzle, which was designed ad hoc, and jetted to the workpiece. After this, once the abrasive has flowed over the workpiece, the abrasive is taken to the second fluidized bed through a dust collector system (cyclone) located on top of it. The abrasive collected is then fluidized by additional supply of working fluid at moderate pressure into the second fluidized bed. Flow back of abrasives and stronger disturbances of the abrasive jet to the hydrodynamic of the second fluidized bed are averted by using star valves at the base of the cyclone. The connection between the two fluidized beds guarantees continuity of the operation, with the level of abrasives inside them kept constant according to the principle of communicating vessels. Finally, the roles of the two fluidized beds and annexes can be automatically reversed, as shown in Fig. 2. Consequently, the abrasive jet jets in the opposite direction as it is now supplied into the workpiece from the opposite side, and so the outgoing abrasive is collected in the first fluidized bed.

Two air filters on top of the fluidized beds prevent the system suffering from massive elutriations of abrasive, and these also evacuate the dispersed fines (produced by the machining) and excess fluidization air. Following this, 'absolute' air filters are used to treat the flux of air and fines. Furthermore, in order to ensure the amount and quality of abrasives is constant during machining, hoppers continuously load fresh abrasives to the fluidized beds. Lastly, the draining of dispersed fines and the reloading of fresh abrasives guarantee the FB-AJM machining capabilities are self-regenerating.

\subsection{Basic principle of machining}

When the abrasive is jetted onto the workpieces, it machines the metal by impinging on it at both high speed and a high impact angle. In particular, the abrasive jet acts preferentially on the peaks and asperities protruding from metal surface by ploughing or even cutting them off. As a result, progressive smoothing of workpiece surface associated with remarkable material removal can be expected.

The effectiveness of FB-AJM must result from the specific characteristics of the abrasive jet. In particular, in contrast to what happens in standard AJM, the fluidized beds mean a fast transport regime can be established inside the workpiece during machining [27]. Consequently, the optimal radial distribution of the abrasive jet across the section of the workpiece is guaranteed, and it minimizes all flux deviations and anomalies inside the workpiece including peculiar abrasive patterns. In addition to this, the uniformity, precision, and accuracy of FB-AJM can also be explained by the above-mentioned reversibility of abrasive direction which results in homogeneous distribution of the machining force of abrasive jet over all the metal surface without interrupting finishing operations. 


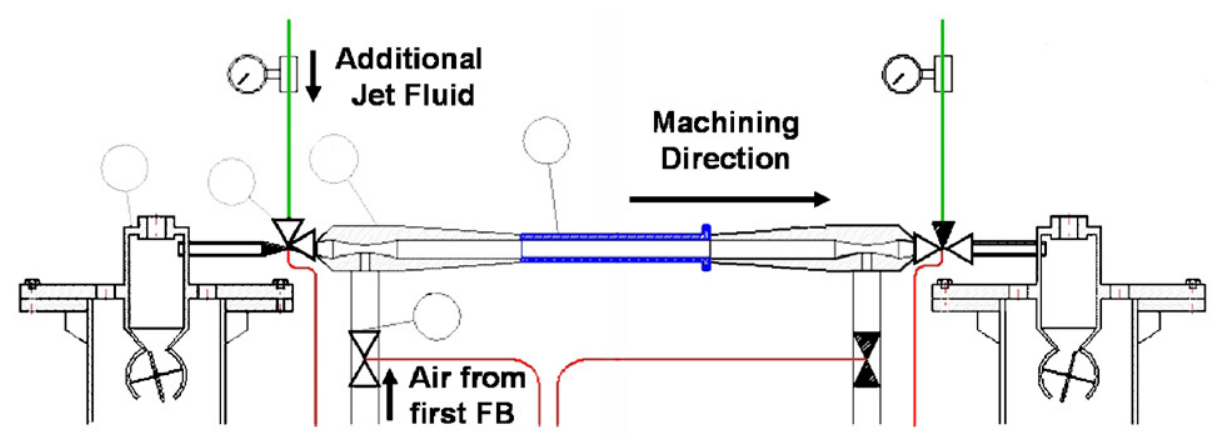

(a) Direct Machining

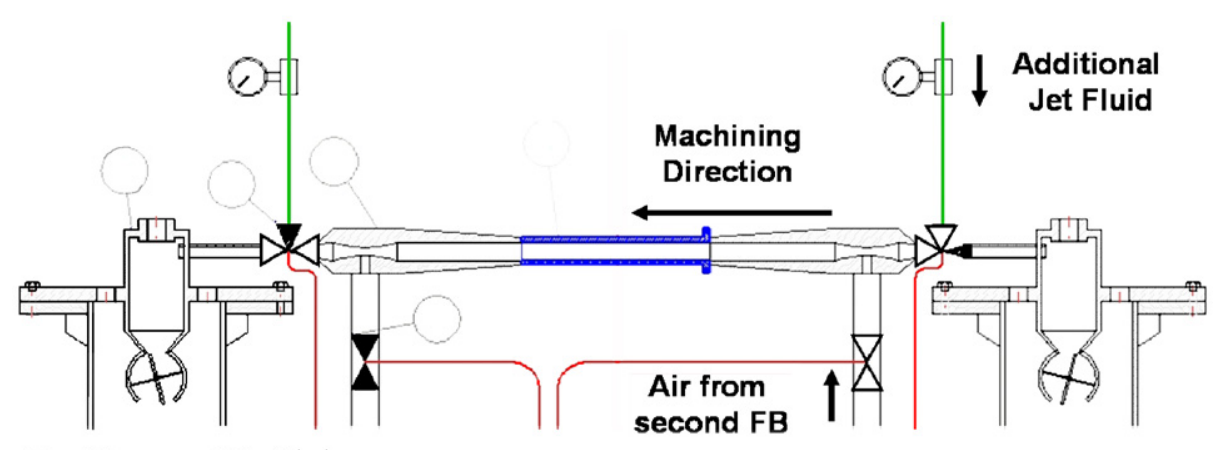

(b) Reverse Machining

Fig. 2. Description of the reversible machining system. Panel (a): direct machining; panel (b): reverse machining.

\subsection{Material and experimental procedure}

A set of workpieces $350 \mathrm{~mm}$ long was cut from an aluminium alloy rod (AA 6082 T6) which was $6 \mathrm{~m}$ long and $20 \mathrm{~mm}$ in diameter. After this, each workpiece was machined by internal longitudinal high-speed turning, with inner diameter being opened at $10 \mathrm{~mm}$.

The abrasive used was angular red-brown alumina $\left(\mathrm{Al}_{2} \mathrm{O}_{3}\right)$ with a mesh size ranging from 24 to 220 , supplied by Smyris Abrasivi $\mathrm{Srl}$ as finely divided powders. The abrasive manufacturer stated hardness of $2300 \mathrm{HV}$ and factor shape of approximately 0.67 . Abrasive jet velocities and machining cycles respectively ranging from 5 to $50 \mathrm{~m} \mathrm{~s}^{-1}$ and from 1 to 8 were investigated. Each machining cycle consisted of the transit of $5 \mathrm{~kg}$ of abrasives over each side of the workpiece (namely side ' $d$ ' and ' $r$ ', Fig. 3). Depending on the jet velocity and abrasive size, each machining cycle lasted from 3 to $10 \mathrm{~min}$. The amount of abrasives passing through the workpieces was checked by measuring the rotation speed of the star valve at the bottom of each cyclone.

Table 2 displays the Taguchi's design developed to examine the influence of operational parameters (i.e. machining speed, abrasive mesh size, and machining cycle) on the experimental response 'surface roughness' and 'material removal'. An L18 mixed 3-6 level design was scheduled using the experimental factors: abrasive mesh size, abrasive jet speed, and number of machining cycles. Each test was replicated four times to ensure the reliability and reproduceability of the experimental results. Once the best settings of operational parameters had been defined (four machining cycles, and jet velocity of $10 \mathrm{~m} \mathrm{~s}^{-1}$ ), they were employed in the second set of experiments, where FBAJM was repeated on workpieces step by step using progressively smaller abrasive sizes, as reported in Table 3.

The experimental protocol was strictly adhered to so that material removal and surface roughness measurements would be reliable. Material removal was estimated using a Sartorious Model BP 211-D weighing instrument with a resolution of $0.01 \mathrm{mg}$. To minimize any disturbance during tests caused by air currents, workpieces were enclosed in a box. Two special stainless steel slabs were kept separately and used as standard weights to calibrate the weighing instrument each time it was used. These particular procedures meant the scales performed the measurements to the required level of accuracy and with good reproduceability.

The weighing procedure followed began by taking the initial weight of the workpiece. Then, in order to compare the workpiece weight before and after machining, a very fine tissue (Kimwipes) was used to clean the surface after the test had been performed. Following this, the workpieces were placed in a dryer at moderate temperature $\left(60{ }^{\circ} \mathrm{C}\right)$. A further passage with the tissue was performed after which weighing was carried out as soon as possible in order to avoid the influence of any dust or oxidation. The workpieces were left on the electronic scales long enough for the weight shown on the digital display to stabilize. Each workpiece was measured several times, and if the difference between the two successive measurements failed 


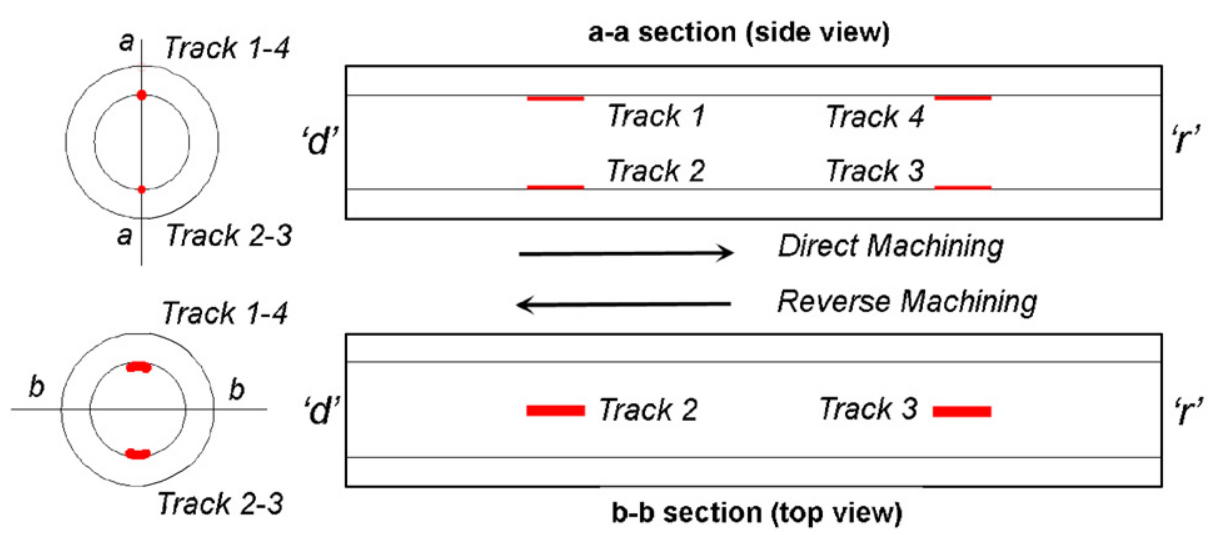

Fig. 3. A sketch of the workpiece: the two abrasive jet directions, namely, ' $d$ ' and ' $r$ ', and the different circumferential locations (1-4) along which roughness measurements were performed.

Table 2

Taguchi's experimental plan

\begin{tabular}{llll}
\hline $\begin{array}{l}\text { Experimental } \\
\text { levels }\end{array}$ & \multicolumn{2}{l}{ Experimental factors } \\
\cline { 2 - 4 } & $\begin{array}{l}\text { Abrasive size } \\
(\mathrm{MS})\end{array}$ & $\begin{array}{l}\text { Jet velocity } \\
\left(\mathrm{m} \mathrm{s}^{-1}\right)\end{array}$ & Machining cycle \\
\hline I & 24 & 10 & 2 \\
II & 40 & 20 & 4 \\
III & 60 & 50 & 8 \\
IV & 80 & - & - \\
V & 120 & - & - \\
VI & 220 & - & - \\
\hline
\end{tabular}

Table 3

Second set of experiments

\begin{tabular}{llll}
\hline $\begin{array}{l}\text { Experimental } \\
\text { levels }\end{array}$ & \multicolumn{2}{l}{ Experimental factors } \\
\cline { 2 - 4 } & $\begin{array}{l}\text { Abrasive size } \\
(\mathrm{MS})\end{array}$ & $\begin{array}{l}\text { Jet velocity } \\
\left(\mathrm{m} \mathrm{s}^{-1}\right)\end{array}$ & Machining cycle \\
\hline I & 24 & 10 & 4 \\
II & 40 & - & - \\
III & 60 & - & - \\
IV & 80 & - & - \\
V & 120 & - & - \\
VI & 220 & - & - \\
\hline
\end{tabular}

to agree within $0.5 \mathrm{mg}$, the measurements were repeated until agreement within this range was obtained in successive determinations.

To measure surface morphology evolution during machining, surface roughness was measured using a standard profilometer (Taylor Hobson model CLI 2000) based on an inductive probe. The experimental data was processed and roughness parameters extrapolated using TalyMap software release 3.1. During roughness measurements, four areas of $7 \times 2 \mathrm{~mm}^{2}$ were scanned along the four directions displayed in Fig. 3. In total 200 profiles, all with a resolution of 1000 points per $\mathrm{mm}$, were acquired to depict the surface morphology at various stages of machining.
Finally, a field emission scanning electron microscope (Leo model Supra 35) was used to take pictures at various levels of magnification and detect the evolution of surface conditions during machining.

\section{Results and discussion}

\subsection{The analysis of process parameters: a statistical approach}

Fig. 4 reports the main effect plots (MEPs) of material removal and average roughness according to all the operational variables, reporting the raw response data. Operational variable 'mesh size' was found to be the most influential factor on the experimental responses 'material removal' and 'average roughness'. In particular, the greater the increase in mean diameter of abrasives distribution, the greater the increase in material removal and the worse the expected values of average roughness. Remarkable main effects on response 'material removal' are reported for both 'machining cycle' and 'jet speed'. On the other hand, much less significant main effects on 'average roughness' response are detected for both 'machining cycle' and 'jet speed'. In particular, an increase in machining cycle and in jet speed produces faster wear of the machined substrates, with the expected values of average roughness mostly remaining unchanged.

The analysis of variance (ANOVA) confirms the analysis of mean (ANOM) results reported in Fig. 4. Tables 4 and 5 report contribution percentages, degrees of freedom, and Fisher's values for each operational variable investigated for the responses of 'material removal' and 'average roughness', respectively. In the case of material removal (Table 4), all the experimental factors were significant, with their Fisher's values quite a lot greater than their tabulated corresponding Fisher's values. Furthermore, percentage of contribution for each experimental factor was found to be rather high, with values ranging from $20 \%$ to $40 \%$. In contrast, the percentage of contribution of factor 'error' is quite low (close to $10 \%$ ), therefore showing how good the reliability of the experimental procedure is. In the latter 

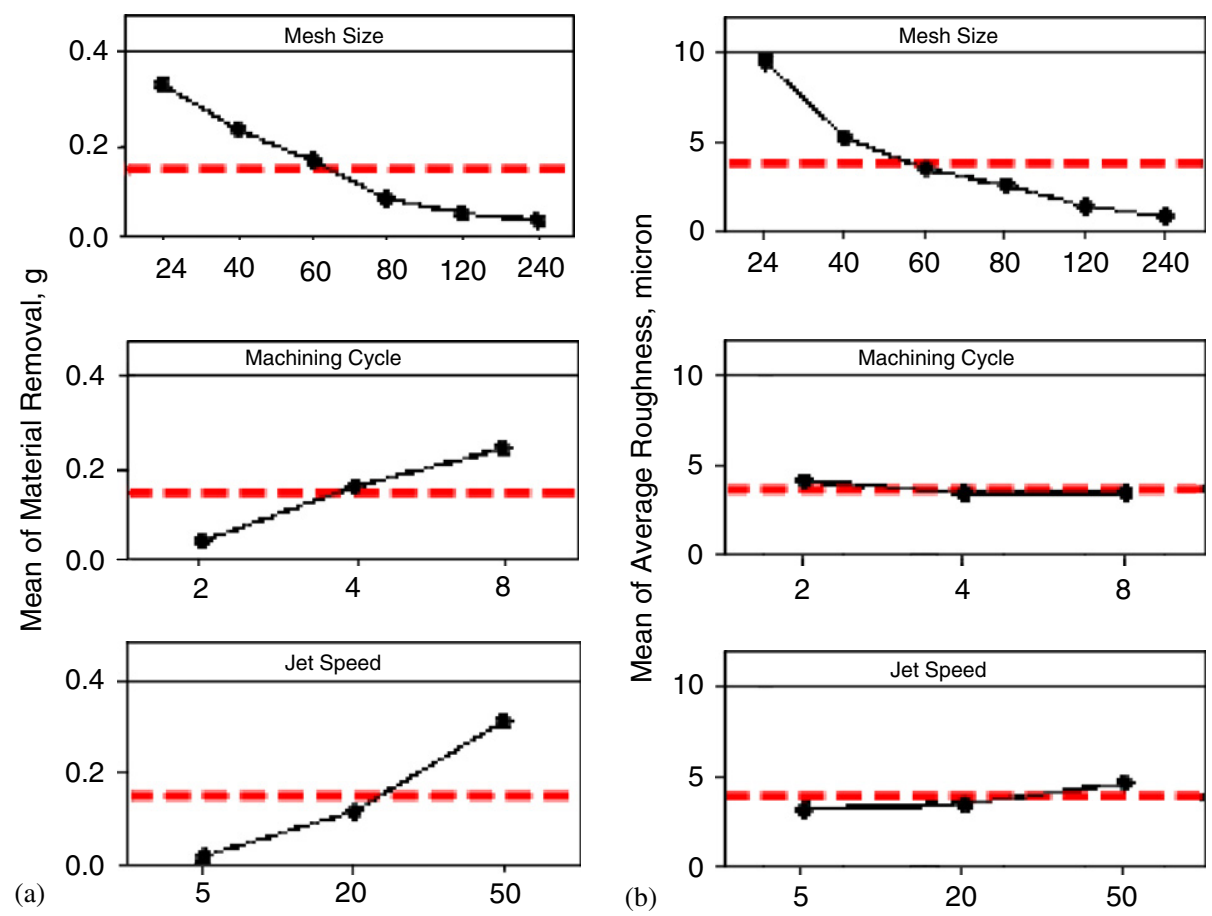

Fig. 4. ANOM on L18 mixed level Taguchi's experimental design.

Table 4

ANOVA table for experimental response 'material removal'

\begin{tabular}{|c|c|c|c|c|c|c|}
\hline Source & DF & Seq SS & Adj SS & Adj MS & $F$ & $p$ \\
\hline Mesh size & 5 & 610.784 & 610.784 & 122.157 & 304.73 & 0.000 \\
\hline Machining cycle & 2 & 6.579 & 6.579 & 3.290 & 8.21 & 0.001 \\
\hline Jet speed & 2 & 28.788 & 28.788 & 14.394 & 35.91 & 0.000 \\
\hline Error & 62 & 24.854 & 24.854 & 0.401 & & \\
\hline Total & 71 & 671.005 & & & & \\
\hline
\end{tabular}

Table 5

ANOVA table for experimental response 'average roughness'

\begin{tabular}{lccccc}
\hline Source & DF & Seq SS & Adj SS & Adj MS & $F$ \\
\hline Mesh size & 5 & 0.76387 & 0.76387 & 0.15277 & 28.19 \\
Machining cycle & 2 & 0.50654 & 0.50654 & 0.25327 & 0.000 \\
Jet speed & 2 & 1.06541 & 1.06541 & 0.53270 & 0.000 \\
Error & 62 & 0.33605 & 0.33605 & 0.00542 & 98.28 \\
Total & 71 & 2.67186 & & & 0.000 \\
\hline
\end{tabular}

case (Table 5), all the Fisher's values were found to be significantly higher than the corresponding Fisher's values tabulated. Nevertheless, examining the percentage of contribution, only the experimental factor 'mesh size' significantly influenced the response 'average roughness' (more than $90 \%$ of contribution) in agreement with indications provided by ANOM. On the other hand, even though $p$-values close to 0 were calculated, the other two experimental factors of jet speed and machining cycle definitely have a minor influence on response 'average roughness' as their contribution percentages are low. Finally, the percentage contribution of factor 'error' is very low, hence once more confirming the reliability of the experimental procedure.

\subsection{The analysis of process parameters: the influence of machining cycle}

Further to the indications provided by MEPs and ANOVA, the surface morphology was studied by using 
the same abrasive to treat a sample in three different zones, but using a different number of machining cycles and with different abrasive jet speeds. The morphologies measured are reported in Fig. 5. The raw 3D maps highlight the better overall behaviour of the surface treated using a
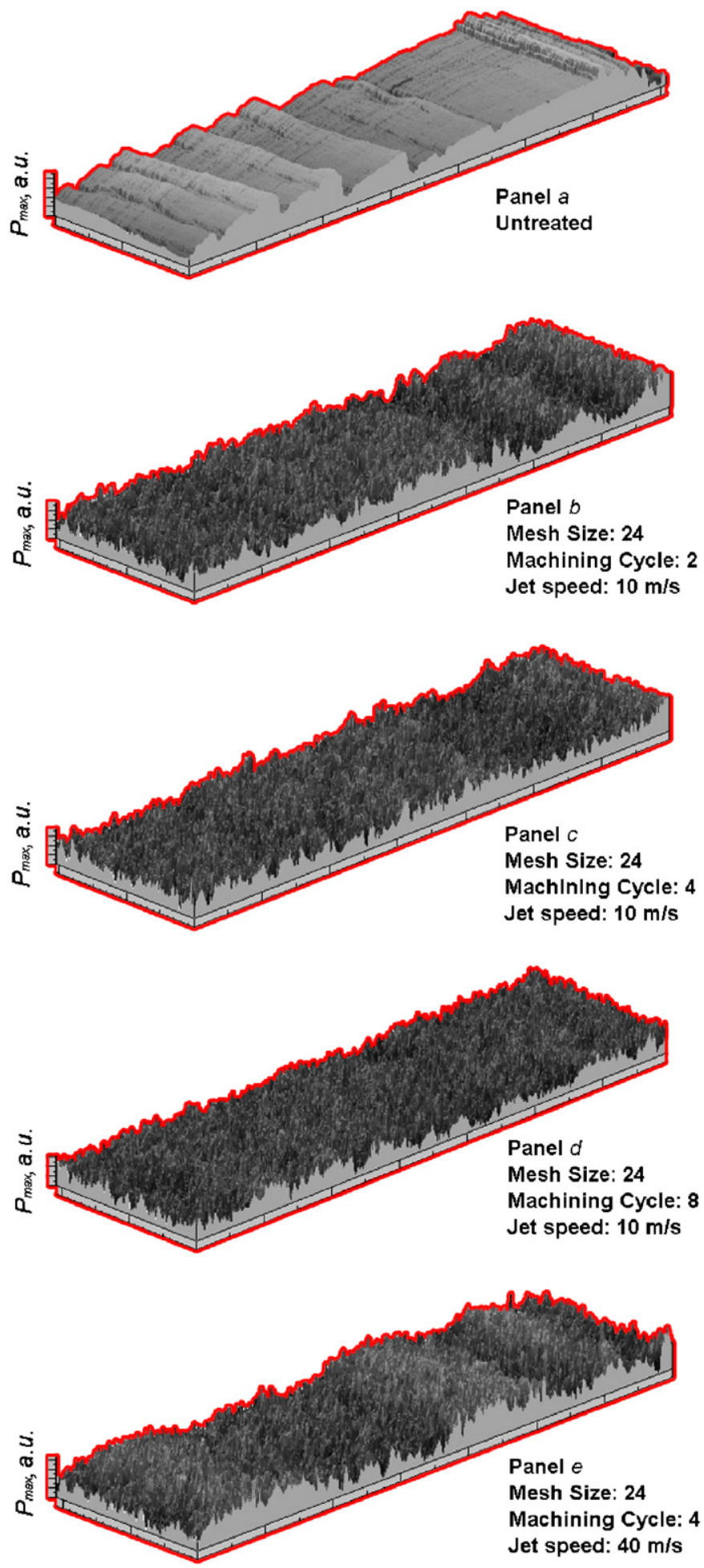

Fig. 5. Influence of machining speed on surface flatness of machined substrates. combination of sufficient machining cycles (4) and low jet speed $\left(10 \mathrm{~m} \mathrm{~s}^{-1}\right)$.

The 3D maps can be interpreted by comparing panels $a$, $b, c$, and $d$ in Fig. 5. It can be seen that surface finishing definitely improves until two machining cycles elapse (Fig. 5 -panel b), whereupon it remains almost constant. Furthermore, the improvement in surface finishing occurs in unison with a remarkable change in overall morphological aspect of the machined surface. If two more machining cycles are performed (Fig. 5-panel c), the overall surface finishing does not improve significantly, but the degree of morphological uniformity continues to increase. If all eight machining cycles are completed (Fig. 5 - panel $d$ ), no significant variation in surface finishing nor in uniformity of morphological appearance is evident. These considerations explain that the finishing mechanism subsequently changes from initial selective removal of surface asperities (peaks) to more uniform removal of material all over the machined surface with further slight decrease of asperities, and following this, to a stabilization of surface roughness and morphology. Consequently, material removal will be very fast during the initial machining cycles, then gradually slowing down when the surface roughness is reduced, and then approach a steady value until a stabilized machined surface is reached.

These results are in good agreement with the data available in the literature. In FB-AJM of stainless steel tubes, a rapid improvement in the average roughness with a concurrent increase in material removal in a short period of time was followed by a stabilization of the finishing process, with progressively slower improvements in the average roughness and the establishment of a standard amount of material removal per unit of time [27]. In both magnetic AJM [24] and standard AJM [19], surface roughness quickly approached asymptotic values, and correlated strongly to the settings of operational variables. Therefore, in the first part of machining material removal is very fast, with this value diminishing significantly when asymptotic conditions were approached [19,24]. In both abrasive [28] and magnetic [29] flow machining, average roughness also approached asymptotic values. Nevertheless, in flow machining processes material removal tended to remain constant during all the finishing operations [28-29].

This difference in material removal trends between flow and jet machining processes can probably be ascribed to the dissimilar finishing mechanisms involved. In particular, material removal in FB-AJM mainly arises from the surface asperities and irregularities (Fig. 5-panel $a$ ), hence profoundly changing the morphology of machined surface (Fig. 5-panel $b$ ). Therefore, when the stabilization of surface morphology is achieved (Fig. 5-panel $c$ ), the mass loss from the surface slows down quickly, so it approaches a steady value (Fig. 5-panel $d$ ). Consequently, FB-AJM acts like a no pressure copying process. On the other hand, from the start material removal in flow machining occurs from both the peaks and valleys of machined surface, 
thence leaving the overall aspect of morphology of machined surface substantially unchanged and guaranteeing uniform mass loss during the course of the entire the process [28-29]. In fact, in contrast to FB-AJM, flow machining processes is mentioned as pressure-copying process [27-29].

\subsection{The analysis of process parameters: the influence of abrasive jet speed}

Further consideration of panels $a, c$, and $e$ in Fig. 5 reveals remarkable differences in achievable surface finishing and morphology in terms of the influence of jet velocity on surface finishing. This is seen in specifically comparing the evolution of surface morphology according to variation in jet speed while both abrasive mesh size and number of machining cycles remain constant. If low jet speed values are used (close to $10 \mathrm{~m} \mathrm{~s}^{-1}$ ), the best finishing is obtained, with only minor morphological irregularities affecting the machined surface. In fact, in these operating conditions the transport regime of abrasive through the workpiece being finished was fast, causing material removal to be activated mainly from asperities and irregularities of machined surface and the concurrent progressive establishment of a smoother surface (panel $c$ ). In contrast, when higher jet velocities were set, the fluidized beds and nozzle design no longer have a positive influence on the hydrodynamic of the fluid-abrasive mix, with abrasive likely to exhibit irregular jumbling on the workpieces. With jet velocity set very close to the highest value (close to $40 \mathrm{~m} \mathrm{~s}^{-1}$ ), the degree of irregular jumbling was expected to increase. As a result, the accuracy of finishing decreased because of material over-removal caused by the aggressive strikes from the jumbling abrasives which caused the machined surface to deteriorate, considerably reducing morphological uniformity (panel $e$ ).

There is also good agreement between these results and the data in the literature [24,28-31]. An optimized jet velocity value of $13 \mathrm{~m} \mathrm{~s}^{-1}$ was analytically found by Kim et al. [24] in their attempt to model a magnetic AJM system, and Barletta et al. found a similar value to be best in FBAJM of stainless steel tubular parts [27]. Moreover, a selflimiting condition imposed by abrasive jet speed on accuracy of theoretical finishing achievable has already been stressed by one of the authors in a previous study of fluidized bed machining of complex-shaped aluminium components [32] as well as in further studies of AJM processes $[23,25-26]$.

A standard machining condition for FB-AJM of AA 6082 T6 tubular parts can be deduced from the results of the statistical approach and those previously obtained from morphological analysis. Four machining cycles and jet velocity set at $10 \mathrm{~m} \mathrm{~s}^{-1}$ should guarantee the best performance and accuracy of finishing process, concurrently minimizing both related problems and operating costs.

\subsection{Analysis of surface morphology}

Fig. 6 displays the trend of roughness parameters vs. mesh size in standard machining conditions, that is, four machining cycles and abrasive jet speed of $10 \mathrm{~m} \mathrm{~s}^{-1}$. Panels $a$ and $b$ in Fig. 6 report the trends of amplitude parameters, while Fig. 7 reports the evolution of roughness profile according to abrasive size. This shows that using abrasives with a smaller mesh size produced a progressively smoother and uniform surface finishing. In particular, the first machining step performed with abrasive mesh size 24 reset the starting topography, with the initial cutting marks produced by high-speed turning quickly disappearing. The next step involved using abrasives of smaller size that progressively reduced the surface asperities and irregularities of machined surface to obtain an almost flat finishing. As a result, average roughness $R_{a}$ decreased from $3-5$ to $0.6-0.7 \mu \mathrm{m}$ and peak to valley distance $R_{z}$ decreased from $20-40$ to $5-6 \mu \mathrm{m}$, with deviations around the mean values being very small. Consequently, an 'improvement ratio' (i.e. ratio between starting and final roughness) ranging from 4 to 7 is evident.

These results are in good agreement with data available in the scientific literature. In particular, they agree with the roughness trends studied by Barletta et al. [27] using FBAJM on tubular workpieces made from hardened stainless steel, and by Kim et al. [24] using MAJM on SUS 304 circular tubes, in which lowering abrasive mesh size produced a progressive improvement in surface finishing. Nevertheless, in these cases, better average roughness values (as low as 0.015 in FB-AJM and 0.2 in MAJM ) could be achieved, stainless steel substrates being much more suitable to abrasive jet finishing than the softer aluminium substrates. On the other hand, comparison with the results obtained by Jain et al. [29] using AFM on aluminium substrates highlights using FB-AJM results in better overall performance. In fact, using AFM obtained an average roughness very close to $1 \mu \mathrm{m}$, starting from an average roughness around $2 \mu \mathrm{m}$ with an improvement ratio' of just 2 .

Panel $c$ in Fig. 6 displays the trend of spacing $R_{\mathrm{sm}}$ vs. abrasive mesh size. It was observed that the continuous decrease in spacing corresponded with the use of abrasive with smaller mesh sizes. In fact, the relatively longer wavelength components of the roughness profile induced onto the surface by high speed turning (Fig. 7, untreated roughness profile) shortened during FB-AJM. The transformation of surface morphology can be ascribed to the features of the FB-AJM process. In fact, as mentioned above and shown in the literature [23-27], in jet machining the abrasives are lined along the lines of the jet fluid, effectively resulting in abrasive chains. The abrasive chains machine the surface, removing material and performing the finishing operation. As the abrasive chain moves through the workpiece at a very high velocity, the chain has no time to make its shape suitable to the shape of surface being machined. As a result, the chain of abrasives behaves like a 
Paenl a
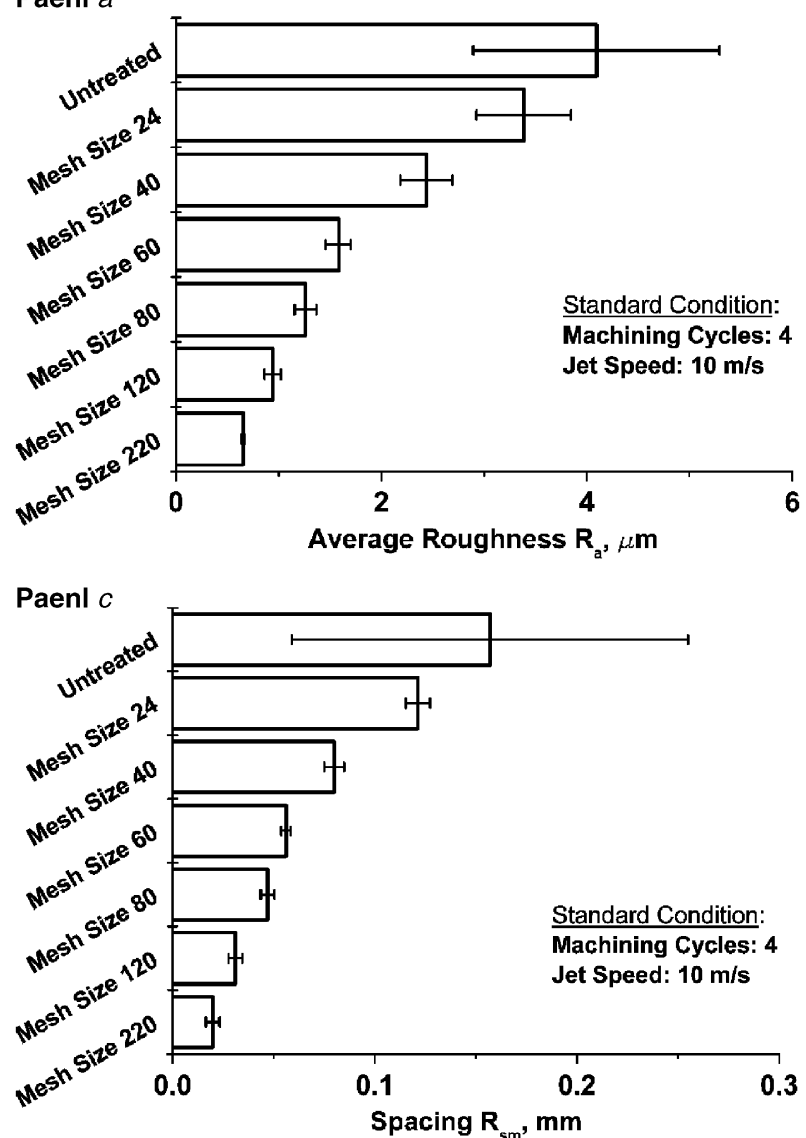

Paenl $e$

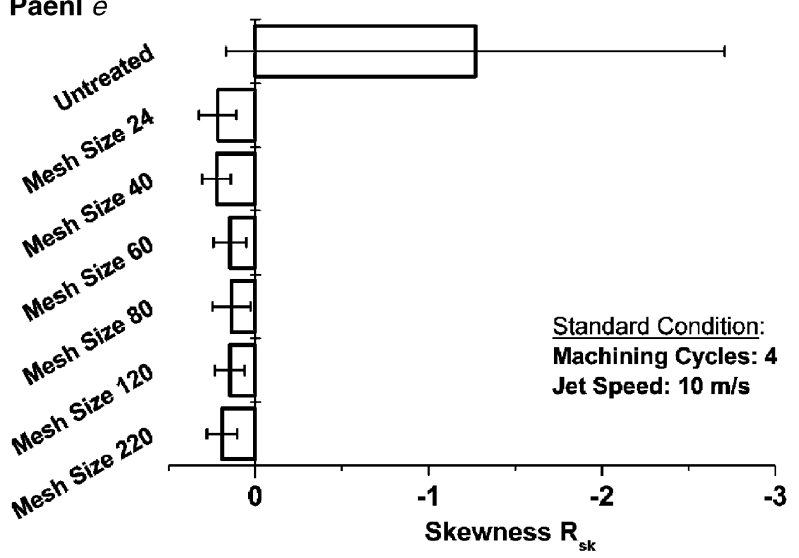

Paenl $b$
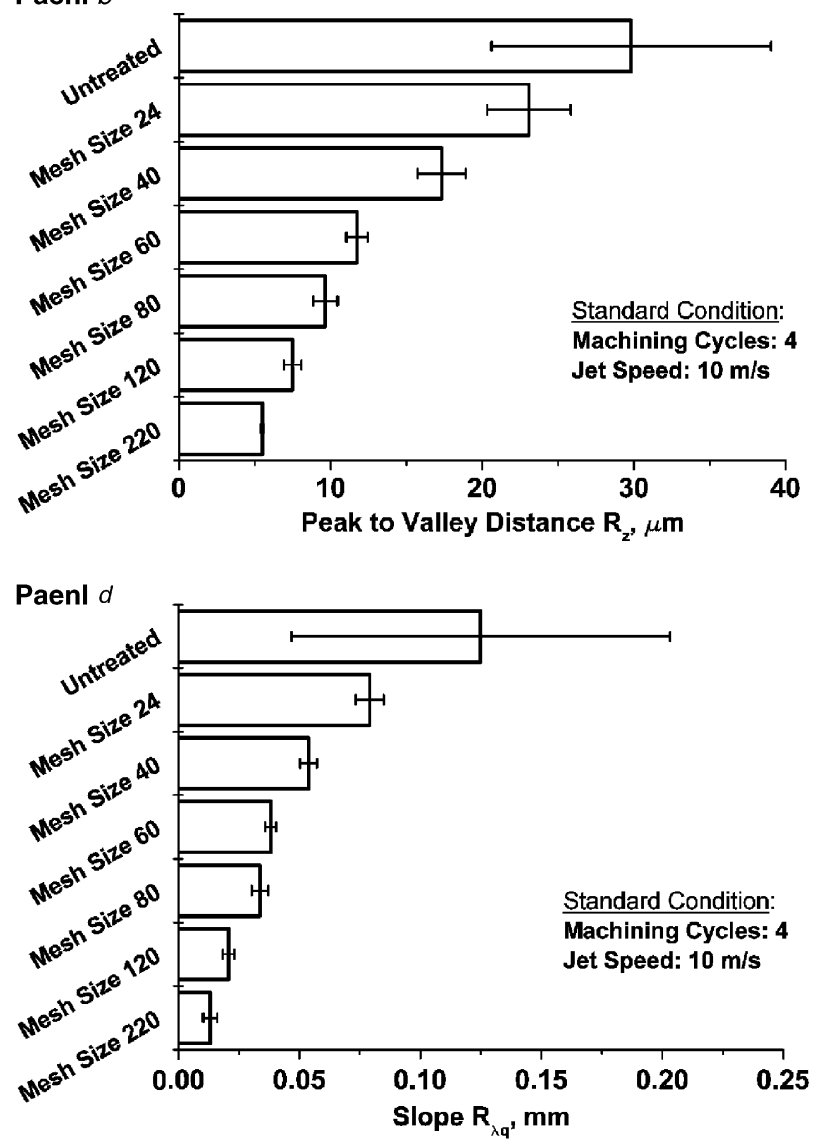

Paenl $f$

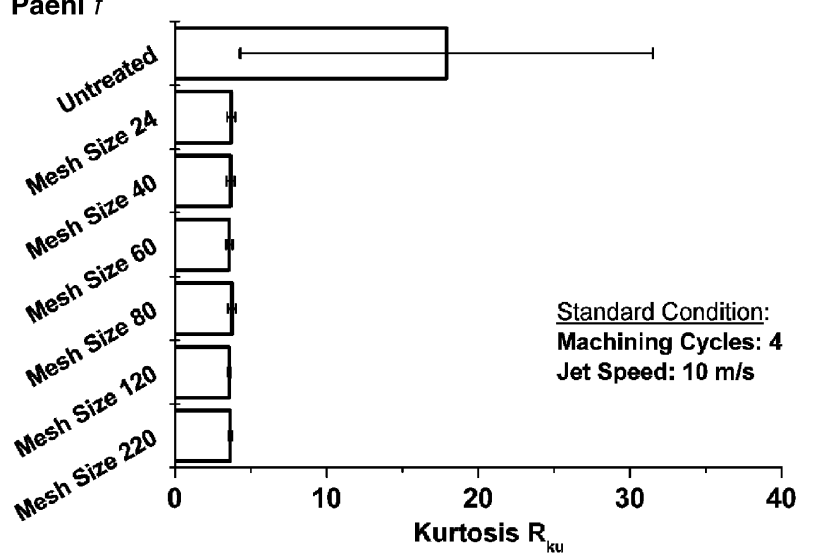

Fig. 6. Roughness parameters vs. abrasive mesh size in standard machining condition.

solid tool, largely removing and displacing material from the peaks of the uneven surface, flattening it and generating a roughness profile with shorter wavelength components (Fig. 7, ranging from 24 mesh size to 220 mesh size roughness profiles).

The evolution of surface roughness profiles shown in Fig. 7 reveals that the cutting edges of the abrasive tend to machine the peaks of the surface and to reduce all the other irregularities on the machined surface. Moreover, the lack of further build up of micro-scratches on the slopes of the starting profile proves that the material is mostly removed from the peaks, leaving the valleys untouched. Conse- quently, as the SEM images reported in Fig. 8 show and the trend in slope $R_{\lambda q}$ in panel $d$ in Fig. 6 confirms, the final surface is composed of an accumulation of shorter wavelength micro-scratches superimposed on a surface clearly flattened by FB-AJM. The smaller the abrasive size employed to finish the surface of the workpiece, the smaller the dimension of the resulting microscratches (from panel $b$ to panel $g$ in Fig. 8), thereby determining an improvement in overall quality of surface finishing. Accordingly, the skewness $R_{\text {sk }}$ and kurtosis $R_{\mathrm{ku}}$ trends progressively assumed more uniform values when smaller abrasive sizes were employed 


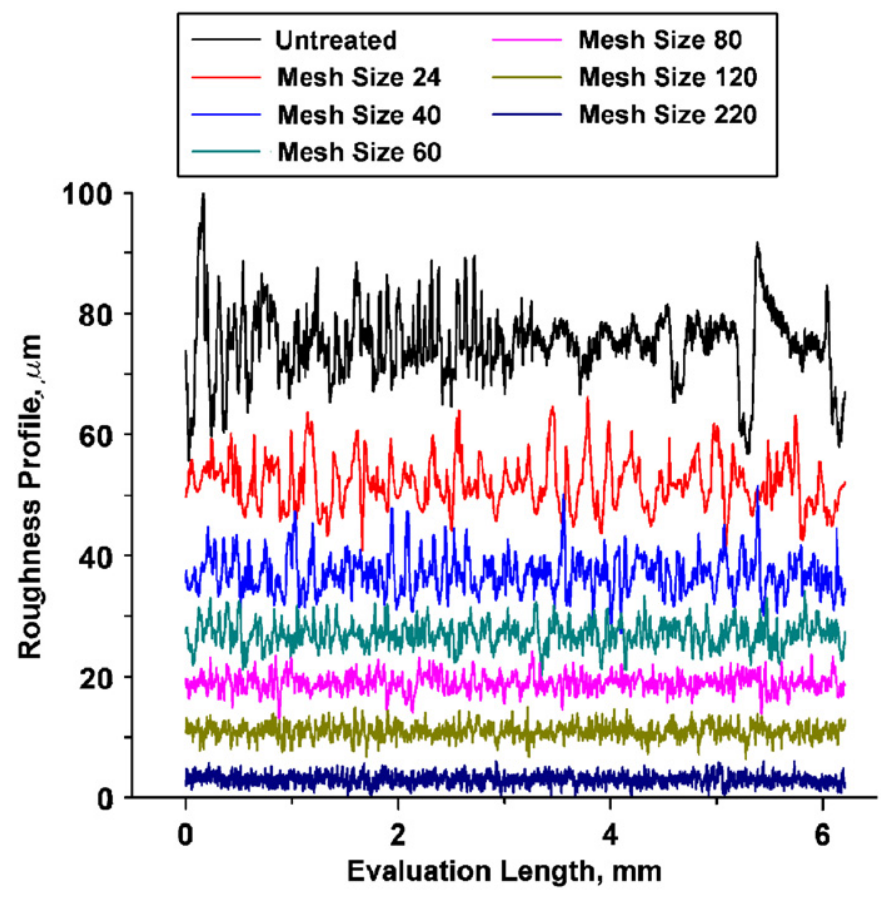

Fig. 7. Roughness profile vs. abrasive mesh size: analysis of $2 \mathrm{D}$ morphology.

(Fig. 6-panels $e$ and f), consequently seeing the profile approach symmetry and normality.

These results are in good agreement with experimental findings in other abrasive jet and flow machining systems, where a peculiar surface texture is always produced after finishing or machining operations [23-24,29].

Fig. 9 shows the SEM photographs of machined surface (standard condition, 120 mesh size) at progressively higher magnification levels. As previously seen, before FB-AJM the surface presented uneven cutting marks caused by the aggressive material removal resulting from the previous high-speed turning process. After finishing, the surface had definitely been smoothed, with the effect of abrasive displacement due to abrasive jet being visible in the cutting marks parallel to the machining direction (panels $a$ and $b$ in Fig. 9).

The effect of material displacement and microcutting action of abrasive edges is clearly visible in panels $c$ and $d$ of Fig. 9, where even the small grooves created by the abrasive impact and the consequent build up of adjacent crests (panel c) can be seen. At the same time, the microcutting action with the residual microchips still standing on the surface can be also observed (panel $d$ ).

The embedding of abrasive splinters can be clearly seen in panel $e$ and $f$ in Fig. 9, where larger splinters of abrasive remained trapped and part of them noticeably stuck out from the metal surface. However, from the first moment of FB-AJM embedding phenomena of alumina splinters were observed all over the machined surface. Rapid saturation of surface with abrasive splinters occurred during the machining. Nevertheless, in employing progressively smal- ler abrasive size, the average size of splinters embedded in the surface decreased, and consequently, the result has a more aesthetically pleasing appearance. Similar results were found in previous studies of fluidized bed machining, which found widespread embedding phenomena of harder abrasive splinters in the softer substrates are recurrent phenomena (alumina splinters in aluminium and brass substrates [32,33], copper splinters in polyamide 6 and 66 substrates [34]).

Fig. 10 shows the uniformity of the roughness profile over the entire machined surface. The trends of average roughness reveal that the surface is uniformly smoothed around the entire internal circumference, with no significant differences in average roughness between all four locations investigated (Fig. 3). This is in marked contrast to the experimental findings reported in the literature for the other AJM systems [23-26], where slight deviations from ideal running of the systems resulted in relevant unevenness of the surface being machined. The difference between FB$\mathrm{AJM}$ and the other systems is probably that the distribution of abrasives across the workpiece section in FB-AJM is uniform, which, as previously stated, avoids flux disturbance, peculiar pattern of abrasives on the workpiece, and jet fluid anomalies. This guarantees uniformity of finishing of all the internal circumference of the machined tubes.

\section{Conclusions}

Experiments were carried out on workpieces of long and narrow circular tubes made of AA 6082 T6. The results obtained are now summarized.

The preliminary Taguchi's experimental plan leads to the following deductions: (i) the machining capability of the developed FB-AJM system is verified by the consistent material removal and average roughness trends (MEPs) in agreement with leading operational variables; (ii) by combined experimental (evolution of raw $3 \mathrm{~d}$ morphology) and statistical considerations (ANOM and ANOVA), a standard machining condition (jet velocity of $10 \mathrm{~m} \mathrm{~s}^{-1}$ and 4 machining cycles) for effective machining of inner surface of workpieces was deduced.

The subsequent experimental tests used progressively lower abrasive mesh sizes, and enabled the following to be deduced: (i) improvement in surface roughness and a sort of asymptotic condition for all the roughness parameters is reached more quickly; (ii) an improvement of average roughness from 3 to $5 \mathrm{~mm}$ to values as small as $0.6-0.7 \mathrm{~mm}$ is obtained quickly; (iii) a progressively more regular surface morphology is seen in the trends of hybrid roughness parameters, whose values increasingly approach more favourable and asymptotic conditions.

These results show that fluidized bed hydrodynamic improves the characteristics of the jet fluid, and consequently of the abrasive configuration and distribution throughout the workpiece, leading to better overall finishing results. 


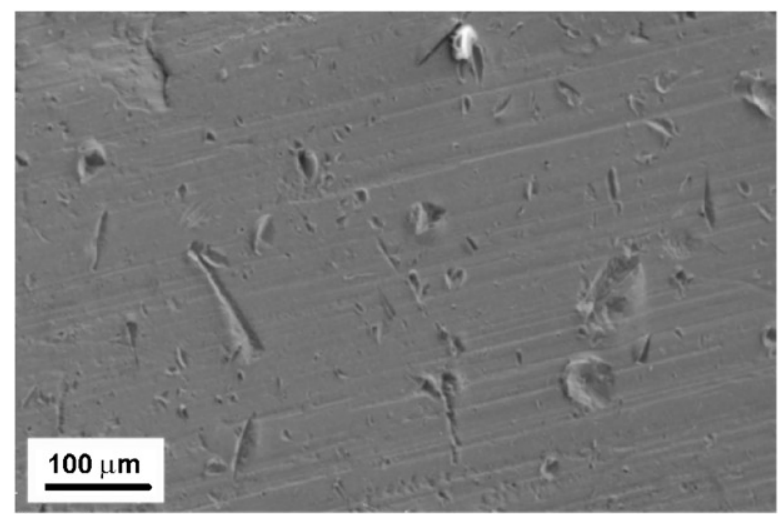

Panel a

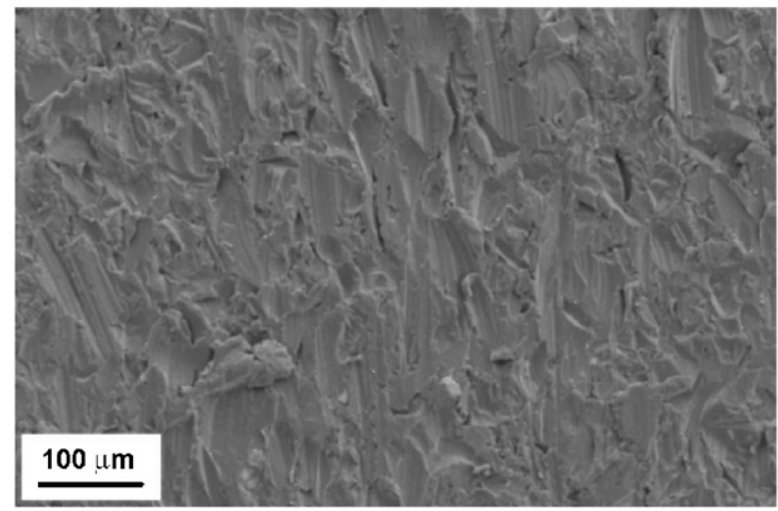

Panel $c$

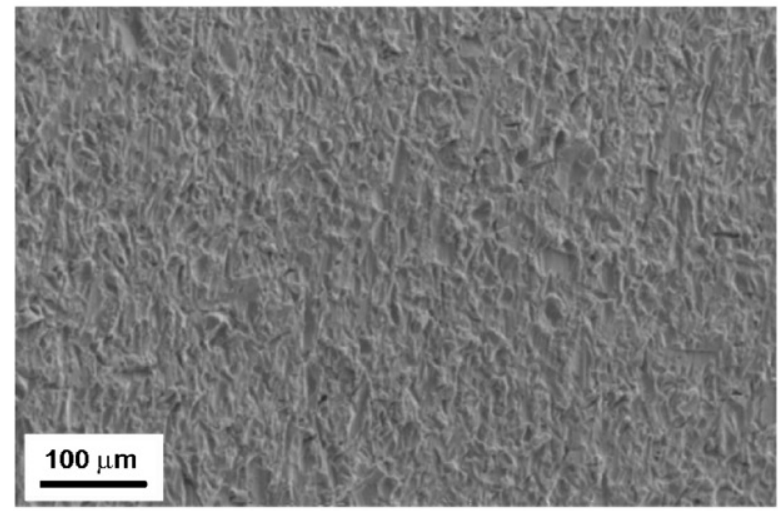

Panel $e$

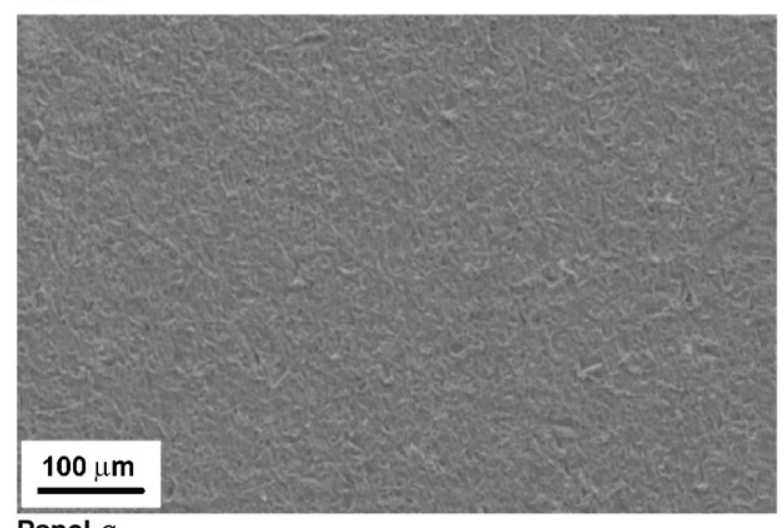

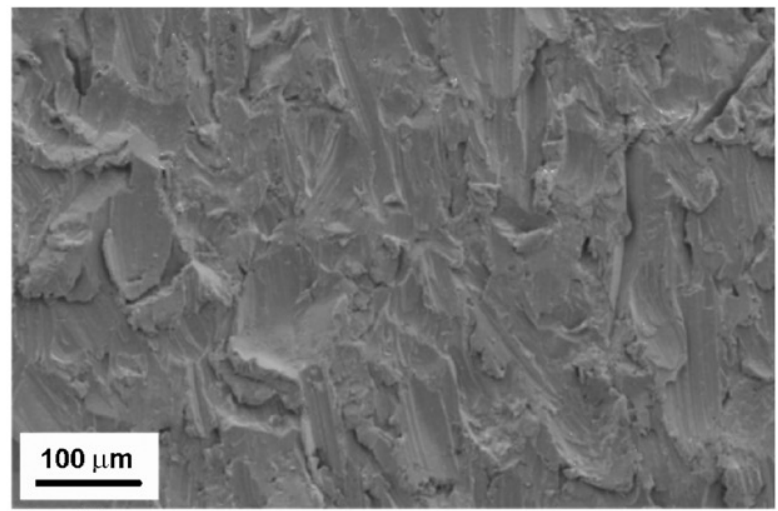

Panel $b$

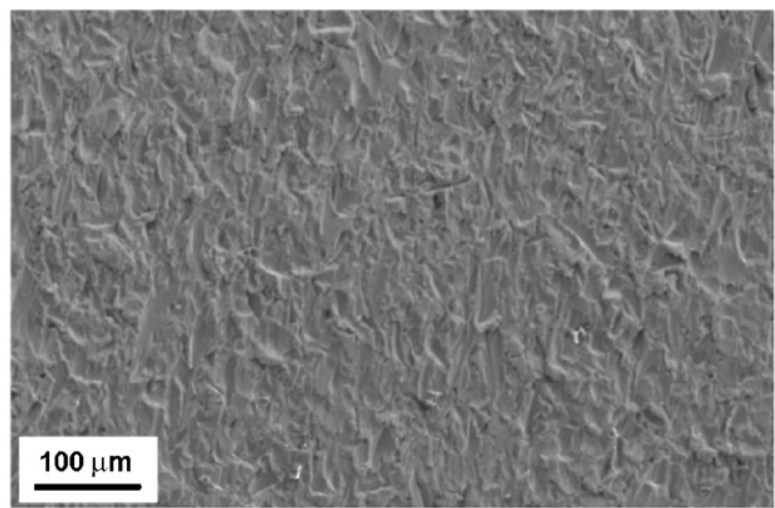

Panel $d$

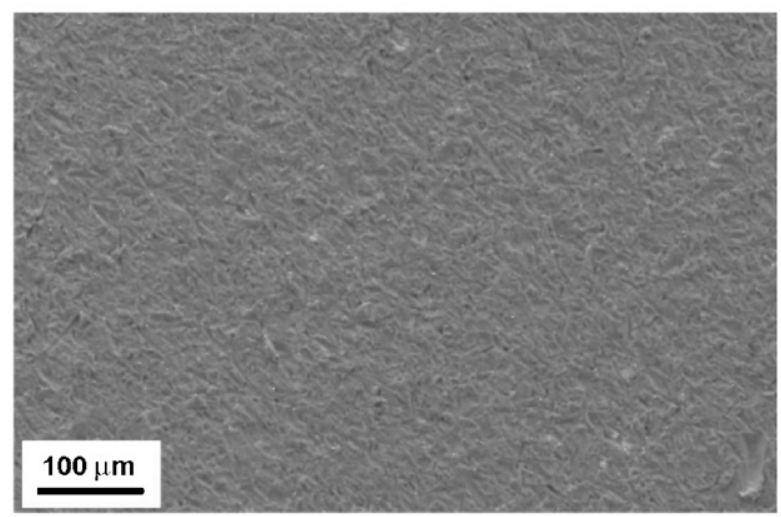

Panel $f$
Panel a : Untreated

Panel $c$ : Mesh Size 40

Panel e : Mesh Size 80

Panel $g$ : Mesh Size 220
Panel b: Mesh Size 24

Panel $d$ : Mesh Size 60

Panel $f$ : Mesh Size 120

Fig. 8. SEM images of surface machined using different abrasive mesh sizes. 


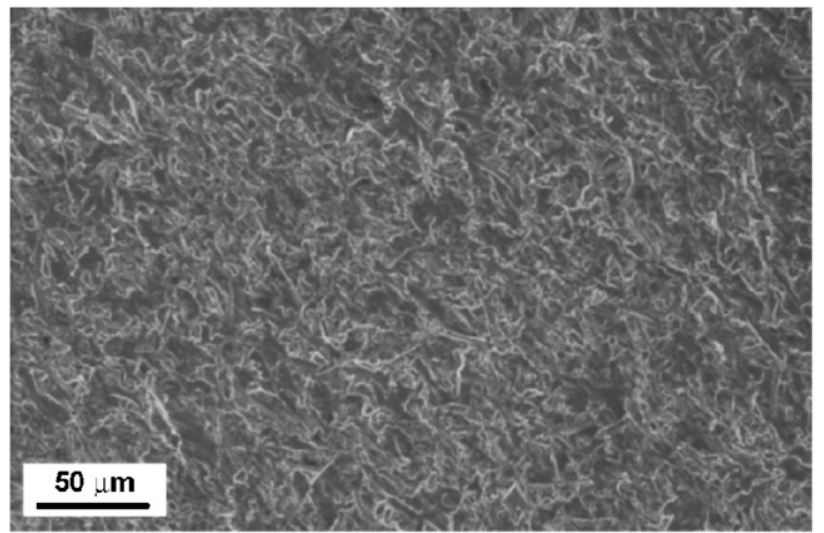

Panel a

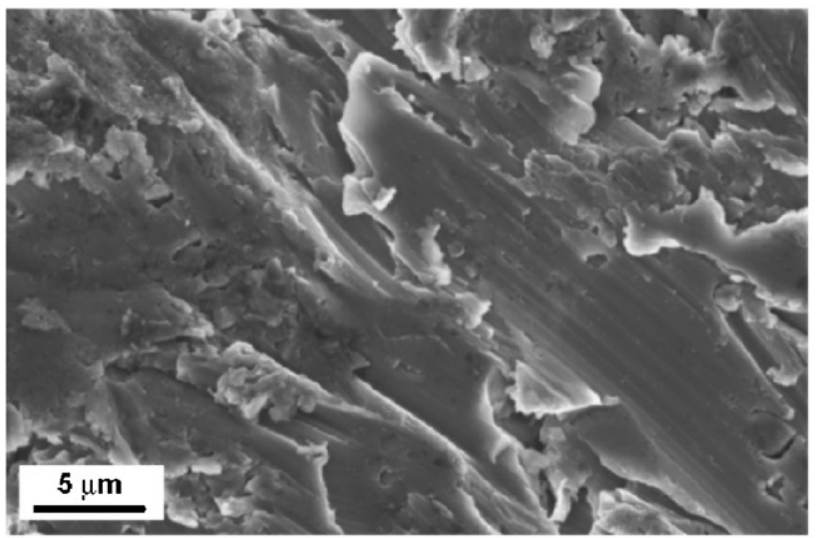

Panel $c$

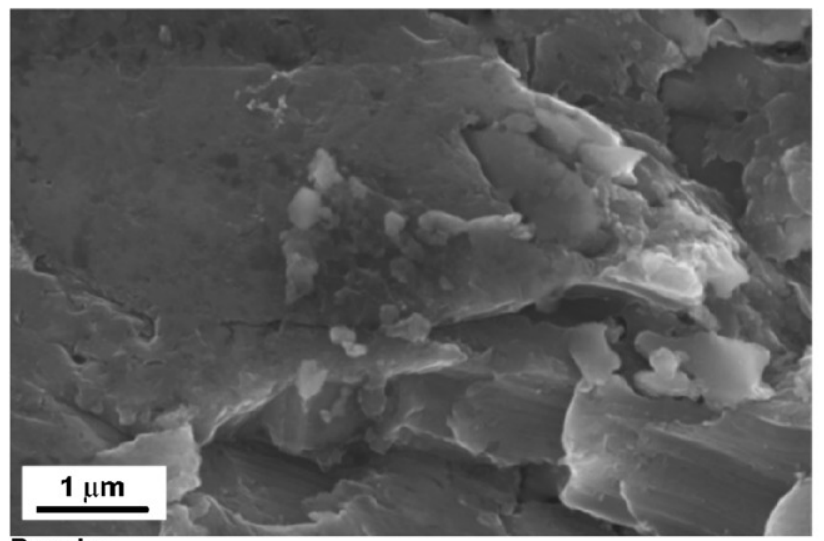

Panel e

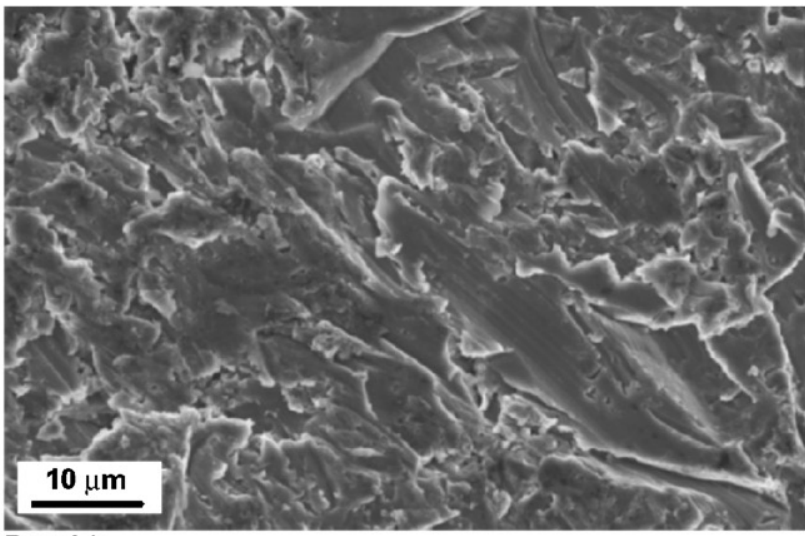

Panel $b$

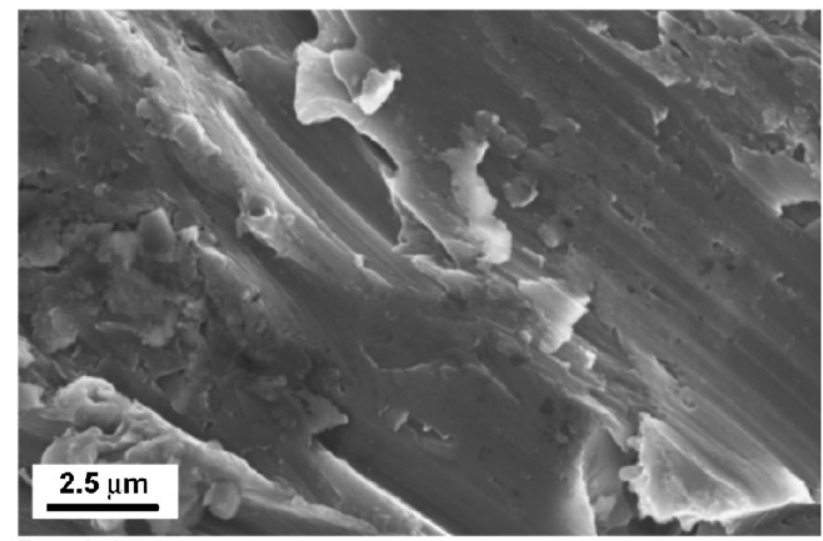

Panel $d$

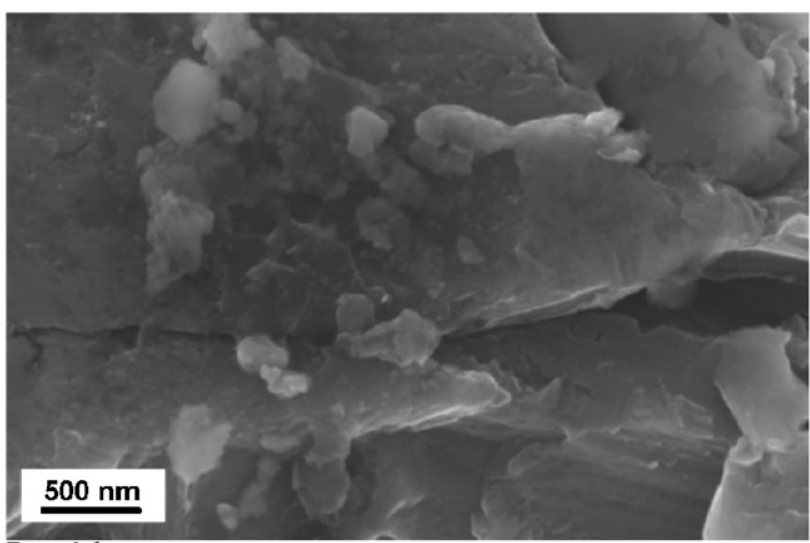

Panel $f$

Fig. 9. SEM images at various magnification level: machining in standard condition using mesh size of 120 .

A combined analysis of $3 \mathrm{D}$ surface profilometry and scanning electron microscope makes an interpretation of material removal mechanism possible as it facilitates the examination of changes in surface texture at a microscopic level. In particular, the following can be deduced: (i) the action of abrasive cutting edges against the surface both cuts asperities into the surface and displaces material; (ii) a remarkable embedding phenomena of the harder abrasive splinters into the softer aluminium matrix is seen and is to be underlined; (iii) in agreement with the trend of spacing $R_{\mathrm{sm}}$, a smoothing of the longer wavelength components of profiles occurs when a progressively smaller abrasive size is used, with the resulting surface being an accumulation of abrasive cutting marks (smaller wavelength components) superimposed on the flattened morphology.

Accordingly, in FB-AJM the abrasive jet is not so flexible as to adapt its hydrodynamic shape to follow the irregularities of surface being machined, and so essentially removes material from the sharper peaks and asperities, thereby changing the morphology, and once more showing that FB-AJM does not belong to pressure-copying finishing processes.

Finally, because of the consistent distribution of abrasive across the section of the workpiece during FB-AJM, good 


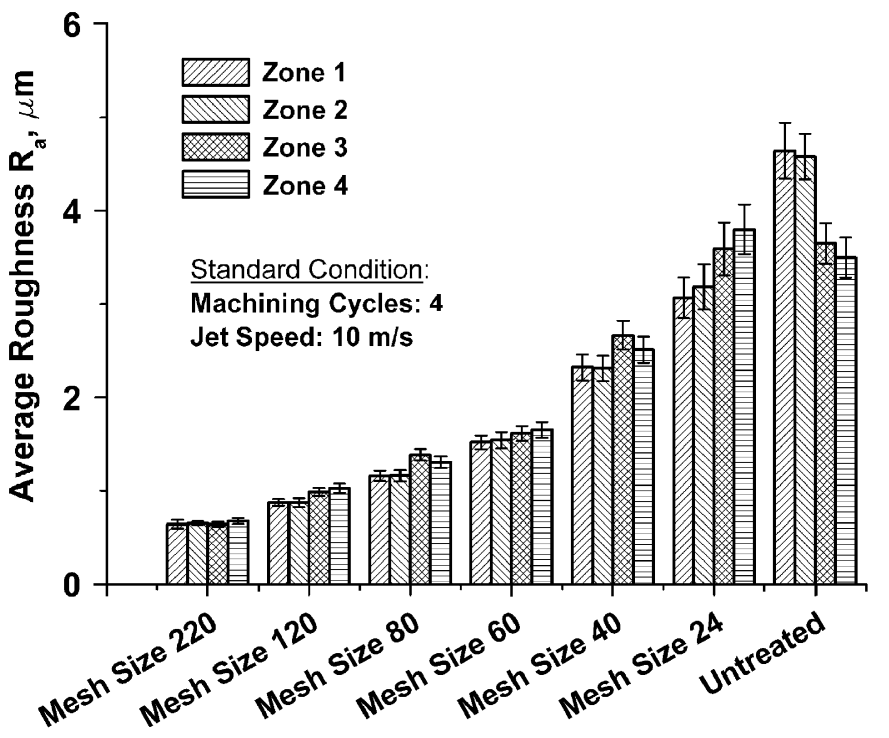

Fig. 10. Average roughness uniformity vs. abrasive mesh size: analysis of four different areas.

uniformity throughout the entire circular shape of the workpiece was obtained.

\section{References}

[1] M.C. Shaw, Principles of Abrasive Processing, Oxford Series on Advanced Manufacturing, Oxford University Press, Oxford, 1996.

[2] J.R. Davis, ASM Metal Handbook, Machining, American Society for Metals, ninth ed., ASM International, 1989.

[3] N.K. Jain, V.K. Jain, Modelling of material removal in mechanical type advanced machining processes: a state-of-art review, International Journal of Machine Tools \& Manufacture 41 (2001) 1573-1635.

[4] P.M. Khodke, D.J. Tidke, Abrasive jet machining: a state-of-art review, Journal of Institution of Engineer 77 (1996) 1-8.

[5] R.K. Jain, V.K. Jain, P.M. Dixit, Modelling of material removal and surface roughness in abrasive flow machining process, Internatinal Journal of Machine Tools \& Manufacture 39 (1999) 1903-1923.

[6] G.Z. Kremen, E.A. Elsayed, V.I. Rafalovich, Mechanism of material removal in the magnetic abrasive process and the accuracy of machining, International Journal of Production Research 34 (1996) 2629-2638.

[7] B.R. Lawn, A model for brittle solids under fixed abrasive conditions, Wear 33 (1975) 369-372.

[8] M. Hutching, A model for the erosion of metals by solid particles at normal incidence, Wear 70 (1981) 269-281.

[9] D.B. Marshall, A.G. Evans, M.E. Gulden, J.L. Roubort, R.O. Scatergood, Particle size distribution effects on the solid particle erosion of brittle materials, Wear 71 (1981) 363-373.

[10] J. Wolak, Parameters affecting the velocity of particle in an abrasive jet, Journal of Engineering Materials and Technology-Transactions of the ASME 99 (1977) 147.

[11] G. Sundararajan, An empirical relation for the volume of crater formed during high velocity oblique impact tests, Wear 97 (1984) 9-16.

[12] P.K. Sarkar, P.C. Pandey, Some investigations on abrasive jet machining, Journal of the Institution of Engineering (India) 56 (1976) 284-287.

[13] M. Hashish, M.P. DuPlessis, Theoretical and experimental investigation of continuous jet penetration of solids, Transactions of the ASME, Journal of the Engineering and Industrialization 100 (1978) 88-94.
[14] M. Hashish, M.P. Du Plessis, Prediction equations relating high velocity jet cutting performance to stand-off distance and multipasses, Transactions of the ASME, Journal of the Engineering and Industrialization 101 (1979) 311-318.

[15] I. Finnie, Erosion of surfaces by solid particles, Wear 3 (1960) 87-103.

[16] J.G.A. Bitter, A study of erosion phenomena: I and II, Wear 6 (1963) $5-21$.

[17] G.P. Tilly, Two stage erosion mechanism of ductile erosion, Wear 23 (1973) 87.

[18] B.R. Lawn, A model for brittle solids under fixed abrasive conditions, Wear 33 (1975) 369-372.

[19] V.C. Venkatesh, T.N. Goh, K.H. Wong, M.J. Lim, An empirical study of parameters in abrasive jet machining, International Journal of Machine Tools \& Manufacture 29 (1989) 471.

[20] A.P. Verma, G.K. Lal, A theoretical study of erosion phenomenon in abrasive jet machining, Journal of Manufacturing Science and Engineering-Transactions of the ASME 118 (1996) 564.

[21] S.S. Rangwala, D.A. Dornfeld, Learning and optimization of machining operations using computing abilities of neural networks, IEEE Transactions on Systems, Man and Cybernetics 2 (1989) 299-314.

[22] G. Chryssolouris, M. Guillot, Modelling of machining process using neural network, Transactions of the ASME, Journal of the Engineering and Industrialization 112 (1990) 122-131.

[23] N. Ramachandran, N. Ramakrishnan, Abrasive jet machining upcoming technology in metal processing: a review****, Journal of Materials Processing Technology 39 (1993) 21-30.

[24] J.-D. Kim, Y.-H. Kang, Y.-H. Bae, S.-W. Lee, Development of a magnetic abrasive jet machining system for precision internal polishing of circular tubes, Journal of Materials Processing Technology 71 (1997) 384-393.

[25] R. Balasubramaniam, J. Krishnan, N. Ramakrishnan, Investigation of AJM for deburring, Journal of Materials Processing Technology 79 (1998) 52-58.

[26] R. Balasubramaniam, J. Krishnan, N. Ramakrishnan, A study on the shape of the surface generated by abrasive jet machining, Journal of Materials Processing Technology 121 (2002) 102-106.

[27] M. Barletta, V. Tagliaferri, Development of an abrasive jet machining system assisted by two fluidized beds for internal polishing of circular tubes, International Journal of Machinery Tools \& Manufacture, approved May 2005, available on line on www.scienceserver.com

[28] H. Yamaguchi, T. Shinmura, Study of the surface modification resulting from an internal magnetic abrasive finishing process, Wear 225-229 (1999) 246-255.

[29] V.K. Jain, S.G. Adsul, Experimental investigation into abrasive flow machining, International Journal of Machine Tools \& Manufacture 40 (2000) 1003-1021.

[30] J. Zhu, J.R. Grace, C.J. Lim, Tube wear in gas fluidized bed-I. Experimental findings, Chemical Engineering Science 45 (1990) $1003-1015$.

[31] J. Zhu, J.R. Grace, C.J. Lim, Tube wear in gas fluidized bed-II. Low velocity impact erosion and semi-empirical model for bubbling and slugging fluidized beds, Chemical Engineering Science 46 (1991) 1151-1156

[32] M. Barletta, A new technology in surface finishing: fluidized bed machining (FBM) of aluminium alloys, Journal of Materials Processing Technology, approved September 2005, available on line on www.scienceserver.com

[33] M. Barletta, G. Costanza, R. Polini, $\mathrm{Al}_{2} \mathrm{O}_{3}$ thin coating of AA 6082 T6 components using a fast regime fluidized bed, Thin Solid Films, approved November 2005, available on line on www.scienceserver.com

[34] M. Barletta, A. Gisario, V. Tagliaferri, Electrostatic spray deposition (ESD) of polymeric powders on thermoplastic (PA66) substrate, Surface and Coatings Technology, approved November 2005, available on line on www.scienceserver.com 